\title{
3D-Printed, Externally-Implanted, Bioresorbable Airway Splints for Severe Tracheobronchomalacia
}

\author{
Andrea S. Les, PhD; Richard G. Ohye, MD; Amy G. Filbrun, MD; Maryam Ghadimi Mahani, MD; \\ Colleen L. Flanagan, MS; Rodney C. Daniels, MD; Kelley M. Kidwell, PhD; David A. Zopf, MD, MS; \\ Scott J. Hollister, PhD; Glenn E. Green, MD (1)
}

Objectives/Hypothesis: To report the clinical safety and efficacy of three-dimensional (3D)-printed, patient-specific, bioresorbable airway splints in a cohort of critically ill children with severe tracheobronchomalacia.

Study Design: Case series.

Methods: From 2012 to 2018, 15 subjects received 29 splints on their trachea, right and/or left mainstem bronchi. The median age at implantation was 8 months (range, 3-25 months). Nine children were female. Five subjects had a history of extracorporeal membrane oxygenation (ECMO), and 11 required continuous sedation, six of whom required paralytics to maintain adequate ventilation. Thirteen were chronically hospitalized, unable to be discharged, and seven were hospitalized their entire lives. At the time of splint implantation, one subject required ECMO, one required positive airway pressure, and 13 subjects were tracheostomy and ventilator dependent, requiring a median positive end-expiratory pressure (PEEP) of $14 \mathrm{~cm} \mathrm{H}_{2} \mathrm{O}$ (range, 6-20 cm $\mathrm{H}_{2} 0$ ). Outcomes collected included level of respiratory support, disposition, and splint-related complications.

Results: At the time of discharge from our institution, at a median of 28 days postimplantation (range, 10-56 days), the subject on ECMO was weaned from extracorporeal support, and the subjects who were ventilated via tracheostomy had a median change in PEEP (discharge-baseline) of $-2.5 \mathrm{~cm} \mathrm{H} \mathrm{H}_{2} \mathrm{O}$ (range, -15 to $2 \mathrm{~cm} \mathrm{H}_{2} \mathrm{O}, P=.022$ ). At median follow-up of 8.5 months (range, 0.3-77 months), all but one of the 12 surviving subjects lives at home. Of the 11 survivors who were tracheostomy dependent preoperatively, one is decannulated, one uses a speaking valve, six use a ventilator exclusively at night, and three remain ventilator dependent.

Conclusions: This case series demonstrates the initial clinical efficacy of the 3D-printed bioresorbable airway splint device in a cohort of critically ill children with severe tracheobronchomalacia.

Key Words: Tracheobronchomalacia, splint, three-dimensional printing, critical care, airway.

Level of Evidence: 4

Laryngoscope, 129:1763-1771, 2019

From the Department of Otolaryngology-Head and Neck Surgery (A.S.L., C.L.F., D.A.Z., G.E.G.); Department of Cardiac Surgery (R.G.o.); Department of Pediatrics, Division of Pediatric Pulmonology (A.G.F.); Department of Radiology (м.G.m.); Department of Pediatrics, Division of Critical Care Medicine (R.c.D.), and Department of Biostatistics (к.м.к.), University of Michigan, Ann Arbor, Michigan; and the Department of Biomedical Engineering (s.J.H.), Georgia Institute of Technology, Atlanta, Georgia, U.S.A.

Editor's Note: This Manuscript was accepted for publication on January 22,2019 .

Presented in part at the Society of University Otolaryngologists Meeting, Chicago, Illinois, U.S.A., November 11, 2017.

G.E.G. and S.J.H. are coinventors on an airway splint patent assigned to the Regents of the University of Michigan. This patent has been licensed by the University of Michigan to Materialise NV, Leuven, Belgium. The University, G.E.G., and S.J.H. could benefit financially if and when the airway splint is commercialized.

This work was funded in part by the National Institutes of Health (NIH) under award number UL1TR002240, UL1TR00043, and 1U01TR002488. This work was also funded in part by NIH grants R21 HD076370 and R01 HD086201 (to S.J.H. and G.E.G.). Device development was funded by NIH grant UL1 RR024986 and Food and Drug Administration grant P50 FD003787.

The authors have no other funding, financial relationships, or conflicts of interest to disclose.

Send correspondence to Glenn E. Green, MD, Department of Otolaryngology-Head and Neck Surgery, Division of Pediatric Otolaryngology, CW-5702 (SPC 4241), 1540 E Hospital Drive, Ann Arbor, MI 48109-4241. E-mail: gegreen@med.umich.edu

DOI: 10.1002/lary.27863

\section{INTRODUCTION}

Tracheobronchomalacia is a condition of dynamic collapse of the trachea or bronchi during respiration. Diagnosis is typically made via bronchoscopy. Mild forms manifest as a cough, wheeze, or impaired secretion clearance. Severe forms have reported mortality rates up to $80 \% .^{1}$ Tracheobronchomalacia can be idiopathic or associated with prematurity, cartilaginous, or other genetic syndromes, congenital cardiovascular anomalies, or tracheoesophageal fistulas. ${ }^{2,3}$

Current therapies for severe tracheobronchomalacia include tracheostomy with prolonged mechanical ventilation, ${ }^{4}$ aortopexy, ${ }^{5}$ tracheobronchopexy, ${ }^{1,6}$ and intraluminal metallic, ${ }^{7,8}$ silicone, ${ }^{9}$ or bioresorbable ${ }^{10-12}$ stents. However, these options carry a significant risk of morbidity and mortality, variable efficacy, and a subset of children still suffer acute life-threatening events despite these interventions. In one study of 47 children with tracheobronchomalacia hospitalized in an intensive care setting, 28 (60\%) died. ${ }^{3}$

For all but severe cases, if a child can be supported for 24 months, natural airway growth and maturation resolves symptoms. ${ }^{4}$ We have developed a three-dimensional 
(3D)-printed, externally-implanted, bioresorbable airway splint that provides luminal support for at least two years, and is subsequently resorbed, obviating the need for surgical removal. Results of the first patient, ${ }^{13}$ and then the first three patients were reported previously ${ }^{14}$; here we report clinical outcomes of all 15 children who received splints at our institution through July 2018.

\section{MATERIALS AND METHODS}

\section{Patient Selection}

Only children who were at high risk of death or permanent disability were considered for airway splinting. This included lifethreatening events associated with tracheobronchomalacia, mechanical ventilation requiring prolonged sedation, and airway erosion. Cross-disciplinary consultation was utilized to ensure that airway splinting did not constitute futile care. Children were not excluded for tracheobronchomalacia distal to the areas able to be splinted, severe concomitant pulmonary/cardiovascular disease, extracorporeal membrane oxygenation (ECMO) status, or underlying cartilaginous disorders. Although tracheobronchomalacia is more frequently characterized by circumferential collapse due to weakness of the anterior (cartilaginous) airway, it can also be caused by intrusion of the posterior (membranous) airway. Patients were not excluded based upon type of tracheobronchomalacia. Patients with only one lung were also not excluded.

\section{Splint Design, Manufacturing Process, and Regulatory Process}

The splint design and fabrication process has been detailed previously. ${ }^{14,15}$ Briefly, preoperative inspiratory/expiratory computed tomography (CT) and bronchoscopy were performed to confirm the diagnosis and location of tracheobronchomalacia. Inspiratory and expiratory patient airway models were generated from CT data using Mimics Innovation Suite (Materialise NV, Leuven, Belgium) to determine malacic segment length and diameter; splint designs were then automatically generated from these input data with Custom MATLAB (MathWorks, Natick, MA) code, and subsequently test fit on the patient models. Splints were then 3D printed from $96 \%$ polycaprolactone/4\% hydroxyapatite via laser sintering, and sterilized via ethylene oxide (Nelson Laboratories, Salt Lake City, UT).

Permission from the Food and Drug Administration (FDA) and our institutional review board (IRB) was obtained for each case via the FDA Expanded Access pathway (compassionate use). Informed consent was obtained from each patient's parent or guardian.

\section{Surgical Technique}

Preoperative bronchoscopy was performed to evaluate the airway. A median sternotomy with or without a cervical incision was performed. The anterior and lateral aspects of the trachea and/or mainstem bronchi were isolated, and the area(s) of malacia were confirmed. After choosing the splint(s) of best fit, a series of partial thickness polypropylene sutures were placed circumferentially around the malacic segment(s). The sutures were then passed through the interstices of the splint, and the splints were parachuted down onto the airways. The sutures were then tied, suspending the trachea/bronchi within the splint. Surgical clips denoted proximal and distal ends of the splints for radiographic studies. If the child required concomitant cardiac repair, this was completed after splint implantation. Intraoperative bronchoscopy confirmed patency of the splinted regions.

\section{Data Collection}

For the duration of the study, parents and referring physicians were queried for clinical updates. Once patients surpassed $\geq 1$ year after implantation, families were invited to enroll in a formal survey study to collect information about hospitalizations, illnesses, or adverse events. Separate IRB approval and research consent were obtained for this study.

\section{Statistical Analysis}

Respiratory variables, length of hospitalization, age at implantation, and length of follow-up were collected. For this series of 15 patients, data were descriptive and reported as medians and ranges. For the 12 patients with positive end-expiratory pressure (PEEP) measurements both preoperative and at discharge from our institution, and the nine with PEEP measurements at last follow-up (i.e., on positive pressure ventilation), differences were calculated and the median change was compared to zero via the sign test. McNemar's test compared pre- to postsurgical numbers of patients with chronic hospitalization and ECMO or continuous ventilation for the 12 patients with both measures. The cumulative incidence function of the time (months) to discontinuation of daytime mechanical ventilation was estimated and plotted using an unadjusted Fine-Gray mode ${ }^{16}$ in the presence of competing risks (death).

\section{RESULTS}

From February 2012 to July 2018, 29 splints were implanted in 15 children. Median age at implantation was 8 months (range, 3-25 months). Nine children were female. The median follow-up was 8.5 months (range, 0.3-77.1 months). Implanted splints included $10(35 \%)$ tracheal, $12(41 \%)$ left mainstem bronchus (LMB), and seven (24\%) right mainstem bronchus (RMB) splints. The LMB was more commonly splinted than the RMB, secondary to an increased incidence of vascular compression. Ten children had splints implanted in more than one location. The average sizes of the tracheal, LMB, and RMB splints were (inner diameter $\times$ length in millimeters): $13.3 \times 21.2,8.7 \times 13.0$, and $9.4 \times 9.1$, respectively.

Comorbidities and indications for airway splinting are presented in Table I. The primary indication for splinting was cardiopulmonary life-threatening events in 12 patients (including five with a history of ECMO), lifethreatening tracheostomy tube erosion and failure to wean from mechanical ventilation in one patient, failure to wean from mechanical ventilation in one patient, and social factors necessitating avoidance of a tracheostomy in one patient. All patients had previous surgical attempts to address tracheobronchomalacia, and all but one was tracheostomy and ventilator dependent. Eleven patients required sedation to maintain adequate ventilation, and of those, six also required paralytics. Thirteen patients were hospitalized in an intensive care setting prior to transfer to our institution, unable to be discharged home, and seven had been hospitalized their entire life. Six patients were born before 37 weeks of gestation. Two children had congenital absence of the right lung and had previously underdone long-segment slide tracheoplasties for tracheal stenosis.

All 15 patients had intrathoracic tracheobronchomalacia, and a median sternotomy was performed, 10 of which were re-sternotomies. Two patients also had 
TABLE I.

Comorbidities and Indications for Airway Splinting.

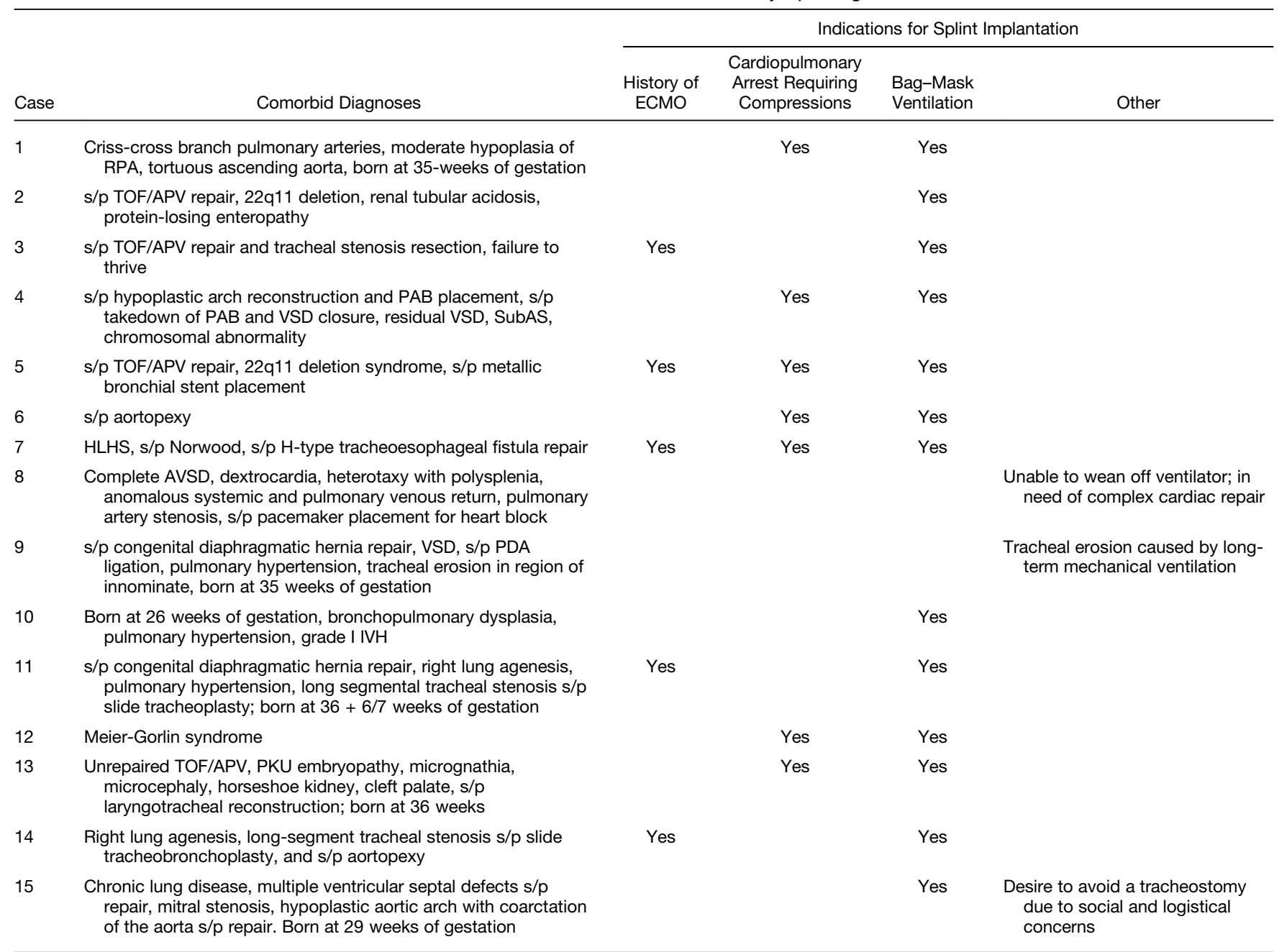

ECMO = extracorporeal membrane oxygenation; RPA = right pulmonary artery; $s / p=$ status post; TOF/APV = tetrology of fallot with absent pulmonary valve; $\mathrm{PAB}=$ pulmonary artery band; VSD = ventricular septal defect; SubAS = subaortic stenosis; HLHS = hypoplastic left heart syndrome; AVSD = atrioventricular septal defect; IVH = intraventricular hemorrhage; $\mathrm{PKU}=$ phenylketonuria.

tracheobronchomalacia that extended just distal to the tracheostomy stoma, and a cervical incision was also performed. Three patients had solely or predominantly posterior tracheobronchomalacia.

Cardiopulmonary bypass is not required for splint placement, except as indicated for cardiorespiratory instability. Bypass was used during splint placement in the first five patients and for only one of 10 subsequent patients. One child had splints placed while on ECMO. Eight patients had cardiac or vascular defects that were addressed during the same surgery immediately after splint placement. Age and year of implantation, and preoperative clinical status are presented in Table II. No patient required splint removal or reoperation for their splint(s).

Preoperatively, all but one patient were tracheostomy and ventilator dependent, requiring a median PEEP of $14 \mathrm{~cm} \mathrm{H}_{2} \mathrm{O}$ (range, 6-20 $\mathrm{cm} \mathrm{H}_{2} \mathrm{O}$ ). Of the 13 patients discharged from our institution who were initially ventilator dependent, one no longer required mechanical ventilation, whereas the median PEEP for the remaining 12 was $8 \mathrm{~cm}$
$\mathrm{H}_{2} \mathrm{O}$ (range, 5-14 $\mathrm{cm} \mathrm{H}_{2} \mathrm{O}$ ) at a median of 28 days postoperatively (range, 10-56 days). For the 12 patients with preoperative and discharge PEEP measures, discharge PEEP levels were significantly lower, with a median change from discharge to preoperative of $-2.5 \mathrm{~cm} \mathrm{H}_{2} \mathrm{O}$ (range, -15 to $2, P=.022)$. In total, 12 patients were transferred back to their referring institution, two were discharged home, and one died prior to discharge. At a median follow-up of 8.5 months (range, 0.3-77 months), 12 patients are longterm survivors, and all but one (a recent case) live at home. Among nine patients who still have a tracheostomy at last follow-up, PEEP values (daytime) continued to decrease, with a median change from most recent to preoperative of $-14 \mathrm{~cm} \mathrm{H}_{2} \mathrm{O}$ (range, -16 to $-4 \mathrm{~cm} \mathrm{H}_{2} \mathrm{O}$, $P=.004)$. A summary of preoperative and postoperative clinical outcomes are listed in Tables II and III. At last follow-up, of the 12 survivors, one patient remains hospitalized, and only three require continuous mechanical ventilation (Fig. 1). Median time to discontinuation of daytime mechanical ventilation (or cumulative incidence 
TABLE II.

Age and Year of Implantation and Preoperative Status of the Splint Patients.

\begin{tabular}{|c|c|c|c|c|c|c|c|c|}
\hline \multirow[b]{2}{*}{ Patient } & \multirow[b]{2}{*}{$\begin{array}{l}\text { Age at } \\
\text { Implantation, } \\
\text { mo }\end{array}$} & \multirow[b]{2}{*}{$\begin{array}{l}\text { Year of } \\
\text { Implantation }\end{array}$} & \multicolumn{6}{|c|}{ Preoperative Status } \\
\hline & & & Respiratory Status & $\begin{array}{l}\text { PEEP, } \\
\mathrm{cm} \mathrm{H}_{2} \mathrm{O}\end{array}$ & $\begin{array}{c}\text { Required } \\
\text { Sedation to } \\
\text { Maintain } \\
\text { Ventilation? }\end{array}$ & $\begin{array}{c}\text { Required } \\
\text { Paralytics } \\
\text { to Maintain } \\
\text { Ventilation? }\end{array}$ & $\begin{array}{l}\text { Predominantly } \\
\text { Posterior } \\
\text { Malacia? }\end{array}$ & Living Situation \\
\hline 1 & 3 & 2012 & Trach and vent dependent & 14 & Continuous & Yes & No & PICU for 1.5 months \\
\hline 2 & 16 & 2014 & Trach and vent dependent & 20 & Continuous & Yes & No & $\begin{array}{l}\text { NICU/PICU for entire life } \\
\text { (16 months) }\end{array}$ \\
\hline 4 & 10 & 2015 & Trach and vent dependent & 10 & Continuous & Yes & No & PICU for 2 months \\
\hline 5 & 5 & 2016 & Trach and vent dependent & 14 & Continuous & Yes & No & $\begin{array}{l}\text { NICU/PICU for entire life } \\
\text { (5 months) }\end{array}$ \\
\hline 6 & 4 & 2016 & Trach and vent dependent & 16 & Continuous & No & No & NICU/PICU for 3 months \\
\hline 7 & 8 & $2016^{*}$ & Trach and vent dependent & 10 & Continuous & No & Yes & $\begin{array}{l}\text { NICU/PICU for entire life } \\
\quad(8 \text { months })\end{array}$ \\
\hline 10 & 9 & 2017 & Trach and vent dependent & 14 & Continuous & No & Yes & $\begin{array}{l}\text { NICU/PICU for entire life } \\
\text { (9 months) }\end{array}$ \\
\hline 11 & 6 & $2017^{*}$ & Trach and vent dependent & 14 & Continuous & No & No & PICU for 2 months \\
\hline 12 & 6 & 2018 & Trach and vent dependent & 18 & Continuous & Yes & No & $\begin{array}{l}\text { NICU/PICU for entire life } \\
\text { (6 months) }\end{array}$ \\
\hline 13 & 11 & 2018 & Trach and vent dependent & 14 & No & No & Yes & $\begin{array}{l}\text { Hospitalized entire life } \\
\text { (11 months) }\end{array}$ \\
\hline 14 & 4 & 2018 & $\begin{array}{l}\text { Trach and vent dependent, } \\
\text { on ECMO at the time of } \\
\text { splint implantation }\end{array}$ & On ECMO & Continuous & Yes & No & $\begin{array}{l}\text { NICU/PICU entire life } \\
\text { (4 months) }\end{array}$ \\
\hline 15 & 13 & 2018 & $\begin{array}{l}\text { HFNC during the day, } \\
\text { CPAP at night. }\end{array}$ & $\begin{array}{c}8 \text { (CPAP mask } \\
\text { at night) }\end{array}$ & No & No & No & Hospitalized for 4 months \\
\hline
\end{tabular}

CPAP = continuous positive airway pressure; ECMO = extracorporeal membrane oxygenation; HFNC = high-flow nasal cannula; NICU = neonatal intensive care unit; $\mathrm{PEEP}=$ positive end-expiratory pressure; $\mathrm{PICU}=$ pediatric intensive care unit;

*Follow-up ends at death.

of time to daytime ventilator discontinuation in the presence of competing risks [death]) is 12.0 months (Fig. 2). Severe lobar and/or segmental malacia (distal to mainstem bronchi) was a common finding in children unable to discontinue ventilator support.

Serial magnetic resonance imaging (MRI) was performed in case 1. MRI demonstrated intact splint at 6 and 12 months postoperatively, but evidence of degradation at 38 and 49 months postoperatively (Fig. 3). Representative preoperative and postoperative minimum intensity projection generated images from the expiratory CT scans are presented in Figure 4.

No child required removal or replacement of their splint(s). As of July 2018, the first four children to receive splints are more than 2 years past splint implantation; all are alive with sustained significant clinical benefit. One child later required an aortopexy 2.5 years after splint implantation and subsequently discharge home due to moderate malacia distal to the splinted region.

\section{Complications}

Among the 15 patients receiving 29 splints, there were two complications related to surgical dissection. One entry into the tracheoesophageal fistula repair pouch occurred and was closed primarily. During another dissection, the trachea and mainstem bronchi were both entered at multiple sites due to the extremely thin airway wall, associated with the patient's underlying Meier-Gorlin syndrome. This resulted in two dehiscences, which continue to heal while the patient remains on oral antibiotics.

There were three mortalities. Two patients died with patent airways due to non-splint-related causes. One patient died 7 months after implantation after suffering an arrest secondary to diffuse hemoptysis, a rare, but known, complication of single ventricle anatomy. ${ }^{17}$ An autopsy confirmed the presence of many prominent congested submucosal vessels and abnormal dilated tortuous veins well away from the splints. A second patient died 10 days postoperatively with airways that were patent in the splinted region, after suffering an arrest secondary to $\mathrm{CO}_{2}$ retention and acidosis, complicated by reactive pulmonary hypertension related to parenchymal disease in her single lung.

One patient died of a possible splint-related complication from upper gastrointestinal hemorrhage 6-months postoperatively. Postmortem evaluation revealed that the tracheal splint was displaced from its original position and eroded into the esophagus. The patient's other splint 
TABLE III.

Postoperative Status of the Splint Patients.

\begin{tabular}{|c|c|c|c|c|c|}
\hline \multirow[b]{2}{*}{ Patient } & \multicolumn{5}{|c|}{ Status as of July 2018 (Postoperative) } \\
\hline & Respiratory Status & $\begin{array}{c}\text { Current } \\
\text { PEEP, } \mathrm{cm} \mathrm{H}_{2} \mathrm{O}\end{array}$ & $\begin{array}{l}\text { Required Sedation } \\
\text { to Maintain Ventilation? }\end{array}$ & $\begin{array}{l}\text { Required Paralytics } \\
\text { to Maintain Ventilation? }\end{array}$ & Current Disposition \\
\hline 2 & Decannulated & None & No & No & Home \\
\hline 3 & $\begin{array}{l}\text { Trach dependent; vent dependent at } \\
\text { night only }\end{array}$ & Day: 0, night: 8 & No & No & Home \\
\hline 5 & Trach and vent dependent & 10 & No & No & Home \\
\hline 6 & $\begin{array}{l}\text { Trach dependent; vent dependent at } \\
\text { night only }\end{array}$ & Day: 0 , night: 8 & No & No & Home \\
\hline 7 & $\begin{array}{l}\text { Died } 6.8 \text { months postoperatively with } \\
\text { patent airways; cause: underlying } \\
\text { congenital heart disease }\end{array}$ & $\mathrm{N} / \mathrm{A}$ & $\begin{array}{l}\text { Before terminal } \\
\text { decline, no }\end{array}$ & $\begin{array}{l}\text { Before terminal } \\
\text { decline, no }\end{array}$ & Deceased \\
\hline 10 & $\begin{array}{l}\text { Trach dependent; vent dependent at } \\
\text { night only }\end{array}$ & Day: 0, night: 8 & No & No & Home \\
\hline 11 & $\begin{array}{l}\text { Died at } 10 \text { days postoperatively with } \\
\text { patent airways; cause: underlying } \\
\text { parenchymal (single) lung disease }\end{array}$ & $\mathrm{N} / \mathrm{A}$ & Prior to death, yes & Prior to death, yes & Deceased \\
\hline 12 & Trach and vent dependent & 6 & No & No & Home \\
\hline 13 & $\begin{array}{l}\text { Trach dependent; vent dependent at } \\
\text { night only }\end{array}$ & Day 0, night: 6 & No & No & Home \\
\hline 14 & Trach and vent dependent & 14 (weaning) & Yes, weaning & No & $\mathrm{PICU}$ \\
\hline 15 & $\begin{array}{l}\text { Nasal cannula during the day and } \\
\text { night }\end{array}$ & None & No & No & Home \\
\hline
\end{tabular}

$\mathrm{N} / \mathrm{A}$ = not applicable; PEEP = positive end-expiratory pressure; PICU = pediatric intensive care unit.

was in its expected location. She was also found to have gastric erosions. Autopsy was not able to define the source of the hemorrhage.

\section{Length of Hospitalizations}

Median length of hospitalization prior to transfer to our institution was 113 days (range, 0-501 days). Seven patients were hospitalized their entire lives prior to transfer to our institution. Median length of hospitalization at our institution was 45 days (range, 12-72 days), with the first 14 days occupied by medical assessment and designing, manufacturing, and sterilizing the airway splints for patients who were chronically hospitalized $(\mathrm{n}=13)$ and unable to wait at home during splint manufacture. Two patients were discharged directly home from

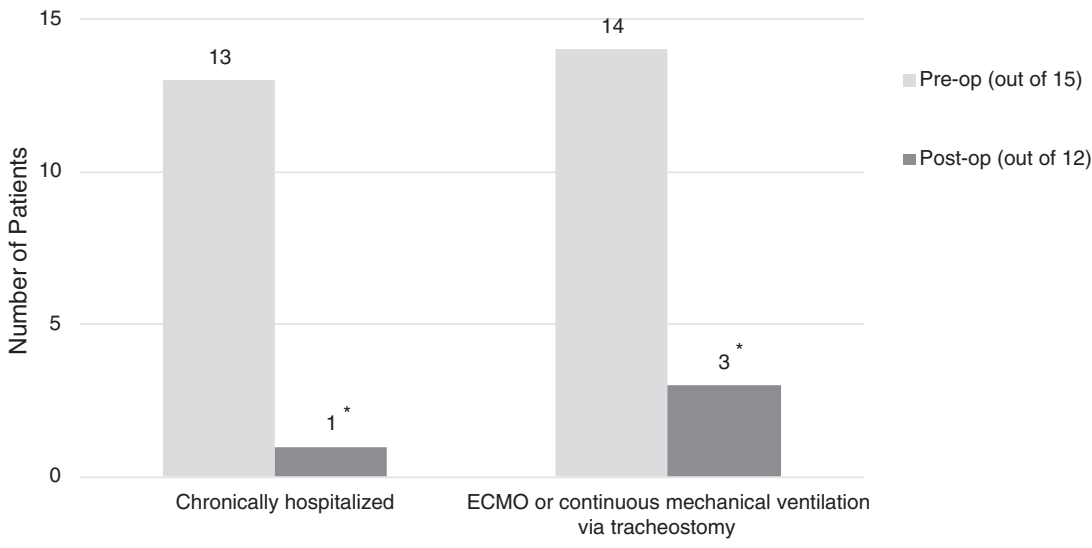

Fig. 1. The number of patients who were chronically hospitalized and who had continuous mechanical ventilation or ECMO, pre- versus postoperatively. The number on top of the bar is the frequency. The 15 children are included preoperatively and 12 postoperatively. $* P<.01$. $\mathrm{ECMO}=$ extracorporeal membrane oxygenation. 


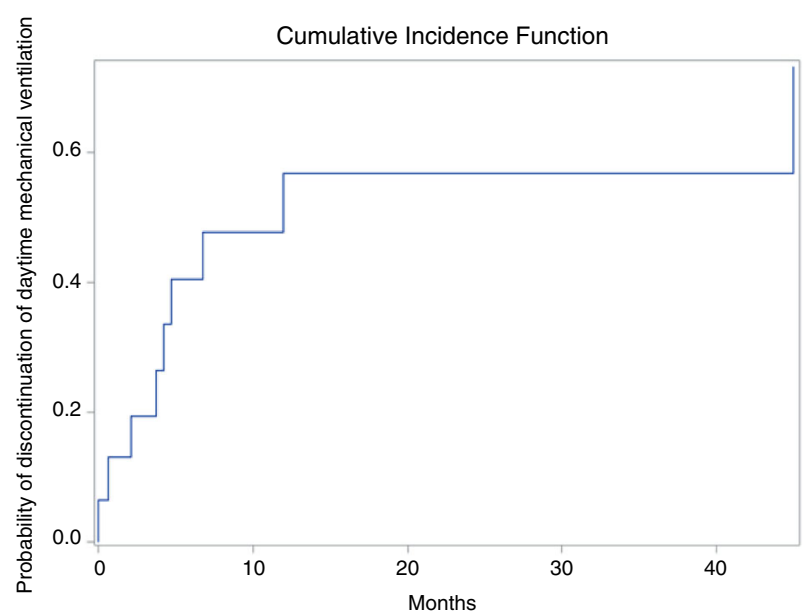

Fig. 2. The cumulative incidence function of the time (months) to discontinuation of daytime mechanical ventilation using an unadjusted Fine-Gray model in the presence of competing risks (death). Seven children were able to discontinue daytime mechanical ventilation within a year of airway splint implantation. [Color figure can be viewed in the online issue, which is available at www.laryngoscope.com.]

our institution at a median of 23 days (range, 11-35 days) following implantation. For the 10 patients who were discharged from their referring institution after back-transfer from our institution, the median length of hospitalization at the referring institution was 62 days (range, 1-285 days). The median total length of hospitalization from splint implantation to discharge home for the 12 patients who survived and were discharged was 73 days (range, 11-315 days).

\section{DISCUSSION}

The severity of pediatric tracheobronchomalacia varies widely. The diagnosis of tracheobronchomalacia is often suspected based on clinical signs and symptoms such as an expiratory wheeze that simulates recalcitrant asthma. However, these clinical findings are neither sensitive nor specific. Endoscopic evaluation remains the gold standard for diagnosis, with flexible bronchoscopy during spontaneous breathing being preferred. In general, $>50 \%$ narrowing of the airway is accepted as diagnostic of tracheomalacia, but classification of severity beyond that remains subjective and ill-defined. ${ }^{18,19}$ In addition to diagnostic bronchoscopy, contrast expiratory/inspiratory CT can aid in identifying specific regions of collapse, degree of distal malacia, and any vascular anomalies. ${ }^{20,21}$

Children with mild TBM typically become asymptomatic after 2 years of age, often with no intervention required. Moderate cases can be treated conservatively with pharmacotherapy, including low-dose inhaled ipratropium or bethanechol, along with chest physiotherapy to improve secretion clearance and treatment of respiratory infections. Moderate-to-severe cases may be managed with continuous positive airway pressure (CPAP) to provide a distending pressure to the airways and prevent collapse on exhalation. More severe cases often present with recurrent pneumonias requiring hospitalization, inability to extubate following illness or procedures, or life-threatening events. These cases may require surgical intervention, which includes aortopexy, tracheobronchopexy, or tracheostomy with or without mechanical ventilation.

A tracheostomy with or without mechanical ventilation is the most common treatment for moderate to severe tracheobronchomalacia. The tracheostomy tube can bypass proximal tracheomalacia and can stent open the mid trachea. A ventilator can then deliver positive pressure to pneumatically stent open the more distal airways. This treatment provides respiratory support until the child can outgrow their malacia as the airway enlarges and the cartilage in their airways strengthens. ${ }^{2,4}$ Complications such as delay in initiation of oral feedings, ${ }^{22}$ developmental delay, and delay in speech and language development have been reported, along with sudden death at home. ${ }^{4,22}$ In one study of 32 premature infants and 18 full-term infants with tracheobronchomalacia, a tracheotomy was required in $24(75 \%)$ of the preterm and seven $(39 \%)$ of the full-term infants. ${ }^{4}$ In these patients, CPAP was used in the management of all of the premature patients and in three $(43 \%)$ of

\section{Splint Degradation by Serial MRI}
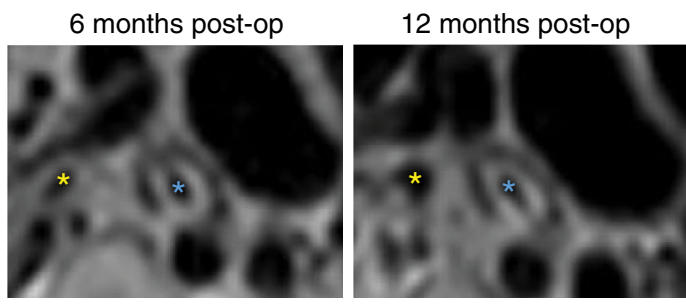

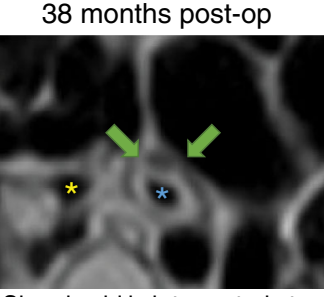

Signal void is interrupted at several points (green arrows)

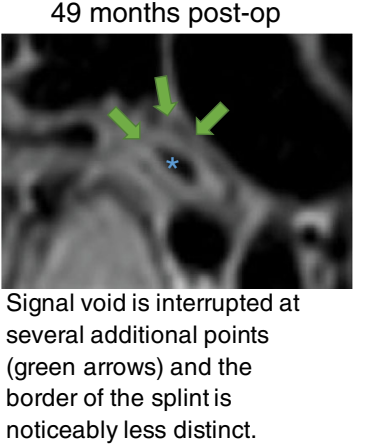

Fig. 3. In serial MRI of patient 1, the splint is represented by a signal void surrounding the left main bronchus. The splint is intact at 6 months and 12 months postoperatively, but shows evidence of degradation at 38 months and 49 months. The yellow star indicates the lumen of the unsplinted RMB. The blue star indicates the lumen of the splinted LMB. MRI = magnetic resonance imaging; LMB = left mainstem bronchus; $\mathrm{RMB}=$ right mainstem bronchus. [Color figure can be viewed in the online issue, which is available at www.laryngoscope.com.] 


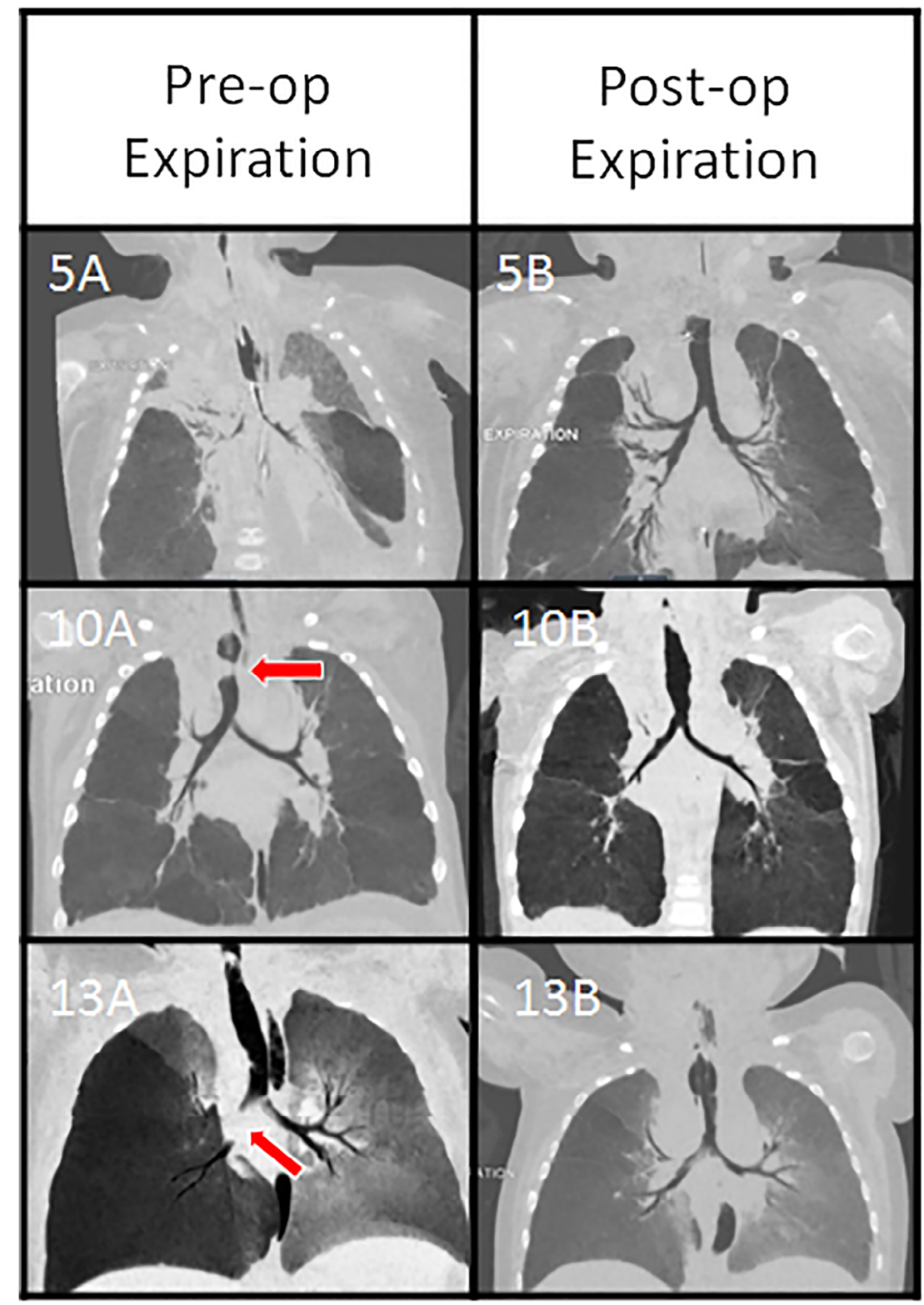

Fig. 4. The location of malacia has varied between patients, as shown in the minimum intensity projections generated from the preoperative (left) and postoperative (right) expiratory computed tomography scans. Patient 5 had severe tracheobronchomalacia, patient 10 had complete expiratory collapse of the midtrachea (red arrow) (10A), and patient 13 had paracarinal malacia and right mainstem bronchomalacia (red arrow). All improved on postsplint images $(5 \mathrm{~B}, 10 \mathrm{~B}$, and 13B). All images were acquired with the tracheostomy tube removed except for image 13B. [Color figure can be viewed in the online issue, which is available at www.laryngoscope.com.]

the seven full-term infants with a tracheotomy. ${ }^{4}$ The average duration of CPAP was 21.4 months for the premature infants and 22.0 months for the full-term infants. There were three deaths in the series.

For the most severe cases, tracheostomy with mechanical ventilation even at extremely high PEEP is often inadequate. In the current study, out of the 14 children with a tracheostomy preoperatively, 13 were experiencing cardiopulmonary life-threatening events despite mechanical ventilation and high levels of PEEP.

Standard anterior aortopexy is commonly used to treat moderate-to-severe tracheobronchomalacia. Aortopexy entails suturing the ascending aorta or aortic arch to the posterior aspect of the sternum. Due to the approximation of the anterior tracheal wall and posterior aorta, this surgery may improve tracheal patency. A metaanalysis of 581 children who received aortopexy for tracheobronchomalacia found that $80 \%$ showed significant clinical improvement, $8 \%$ showed no improvement, $4 \%$ had a worsening of their symptoms, and 6\% died at a median follow-up of 47 months. ${ }^{5}$ However, aortopexy has a high failure rate, particularly for severe cases such as the patients in our series.

Others have tried posterior aortopexy-suturing the descending aorta to the thoracic vertebrae-to address left mainstem bronchomalacia. Unfortunately, in the largest 
study of this technique, eight out of 18 of children were found to have residual severe left mainstem bronchomalacia requiring a tracheostomy $(n=1)$ or placement of internal stents $(\mathrm{n}=7)^{23}$

Jennings has pioneered tracheobronchopexy, ${ }^{6}$ in which the posterior (membranous) trachea is sutured to the anterior spinal ligament and/or the anterior (cartilaginous) trachea and/or bronchi are sutured to the sternum. In a recent case series, authors report no early or late deaths. ${ }^{6}$ A two-stage approach is often required, as is mobilization of the esophagus. Although the technique appears to be efficacious in the trachea and right mainstem bronchus, left mainstem bronchomalacia was relieved in only two out of seven cases. ${ }^{6}$ In contrast, our external splint has been equally effective for the trachea and both mainstem bronchi. In addition, in comparison to our cohort, the patients who received tracheobronchopexy were less critically ill than our cohort. In a later case series by the same group, $13 \%$ of their patients had apparent lifethreatening events preoperatively, considerably less than our cohort, of whom $86 \%$ had documented cardiopulmonary life-threatening events. ${ }^{24}$

In cases where tracheostomy with mechanical ventilation has failed or is contraindicated, other experimental treatments such bioresorbable, silicone, and metallic stenting ${ }^{7-12}$ have been utilized, with varying degrees of success. Internal stenting for tracheobronchomalacia carries significant risk of device migration and obstruction of the airway with silicone stents, ${ }^{9}$ and formation of granulation tissue with resultant airway obstruction with metallic stents. ${ }^{25}$ Bioresorbable internal stents may require serial stenting and involves careful surveillance due to the short resorption time and possible device migration. ${ }^{10}$

Various forms of external splinting have been attempted for severe tracheobronchomalacia refractory to traditional supportive treatment. ${ }^{26,27}$ As early as 1968, ribs were used to externally splint the trachea. ${ }^{28,29}$ In the late 1970s through the 1980s, Filler and colleagues used a silicone elastomer (Silastic) reinforced polypropylene mesh (Marlex) splint, which was applied externally to the airways with mixed results. ${ }^{28,30-32}$ More recently, groups in Germany and Japan described techniques to treat pediatric tracheobronchomalacia via external airway stabilization using polytetrafluoroethylene (PTFE) prostheses. ${ }^{26,33}$ Specifically, Ando et al. reported 98 patients undergoing 127 external PTFE airway stents at a mean age of 7.2 months. $^{26}$ In this series, there were 14 deaths (14\%), including six $(6 \%)$ that were possibly or definitely devicerelated, with twelve patients $(12 \%)$ requiring reoperations, nine for restenosis and three for removal due to perforation of the airway. In comparison, we report three deaths $(20 \%)$ in our cohort, one of which was possibly devicerelated $(7 \%)$, but in a more severe clinical population compared to the PTFE series ( $86 \%$ vs. $37 \%$ with documented cardiopulmonary life-threatening events). No patient in our cohort required splint reoperation.

\section{Limitations}

This is a nonrandomized case series with historical data for comparison of outcomes. All patients were medically complex, with significant comorbidities and prior cardiac, airway, and other interventions. In some cases, concurrent cardiac repair was performed. These factors may confound determining the influence of our device on clinical outcomes. The extent to which the data can be extrapolated to a less critically ill patient population is unknown.

\section{CONCLUSION}

The study presents the clinical results of 15 patients treated with 3D-printed, patient-specific, externally implanted, bioresorbable airway splints. The overall devicerelated complication and mortality rates were low in this population of critically ill, medically complex patients. All surviving patients experienced significant clinical benefit. A pivotal clinical trial is planned in pursuit of FDA approval and subsequent broader application.

\section{Acknowledgments}

The authors gratefully acknowledge the support of the Michigan Institute for Clinical and Health Research Investigational New Drug/Investigational Device Exemption Investigator Assistance Program for their Expanded Access regulatory support.

\section{BIBLIOGRAPHY}

1. Mitchell ME, Rumman N, Chun RH, et al. Anterior tracheal suspension for tracheobronchomalacia in infants and children. Ann Thorac Surg 2014;98: 1246-1253.

2. Carden KA, Boiselle PM, Waltz DA, Ernst A. Tracheomalacia and tracheobronchomalacia in children and adults: an in-depth review. Chest 2005; 127:984-1005.

3. Burden RJ, Shann F, Butt W, Ditchfield M. Tracheobronchial malacia and stenosis in children in intensive care: bronchograms help to predict outcome. Thorax 1999;54:511-517.

4. Jacobs IN, Wetmore RF, Tom LW, Handler SD, Potsic WP. Tracheobronchomalacia in children. Arch Otolaryngol Head Neck Surg 1994;120:154-158.

5. Torre M, Carlucci M, Speggiorin S, Elliott MJ. Aortopexy for the treatment of tracheomalacia in children: review of the literature. Ital J Pediatr 2012; 38:62.

6. Bairdain S, Smithers CJ, Hamilton TE, et al. Direct tracheobronchopexy to correct airway collapse due to severe tracheobronchomalacia: short-term outcomes in a series of 20 patients. J Pediatr Surg 2015;50:972-977.

7. Filler RM, Forte V, Chait P. Tracheobronchial stenting for the treatment of airway obstruction. J Pediatr Surg 1998;33:304-311.

8. Valerie EP, Durrant AC, Forte V, Wales P, Chait P, Kim PC. A decade of using intraluminal tracheal/bronchial stents in the management of tracheomalacia and/or bronchomalacia: is it better than aortopexy? J Pediatr Surg 2005;40:904-907; discussion 907.

9. Fayon M, Donato L, de Blic J, et al. French experience of silicone tracheobronchial stenting in children. Pediatr Pulmonol 2005;39:21-27.

10. Vondrys D, Elliott MJ, McLaren CA, Noctor C, Roebuck DJ. First experience with biodegradable airway stents in children. Ann Thorac Surg 2011;92:1870-1874.

11. Anton-Pacheco JL, Luna C, Garcia E, et al. Initial experience with a new biodegradable airway stent in children: Is this the stent we were waiting for? Pediatr Pulmonol 2016;51:607-612.

12. Serio P, Fainardi V, Leone R, et al. Tracheobronchial obstruction: follow-up study of 100 children treated with airway stenting. Eur J Cardiothorac Surg 2014;45:e100-e109.

13. Zopf DA, Hollister SJ, Nelson ME, Ohye RG, Green GE. Bioresorbable airway splint created with a three-dimensional printer. $N$ Engl J Med 2013; 368:2043-2045

14. Morrison RJ, Hollister SJ, Niedner MF, et al. Mitigation of tracheobronchomalacia with 3D-printed personalized medical devices in pediatric patients. Sci Transl Med 2015;7:285ra264.

15. Hollister SJ, Flanagan CL, Zopf DA, et al. Design control for clinical translation of 3D printed modular scaffolds. Ann Biomed Eng 2015;43:774-786.

16. Fine JP, Gray RJ. A proportional hazards model for the subdistribution of a competing risk. J Am Stat Assoc 1999;94:496-509. 
17. Averin K, Byrnes JW, Benscoter DT, et al. Life-threatening airway bleeding after palliation of single ventricle congenital heart disease. Heart 2018; 104:254-260.

18. Hysinger EB. Laryngomalacia, tracheomalacia and bronchomalacia. Curr Probl Pediatr Adolesc Health Care 2018;48:113-118.

19. Hysinger EB, Panitch HB. Paediatric tracheomalacia. Paediatr Respir Rev 2016;17:9-15.

20. Lee EY, Boiselle PM. Tracheobronchomalacia in infants and children: multidetector CT evaluation. Radiology 2009;252:7-22.

21. Lee EY, Mason KP, Zurakowski D, et al. MDCT assessment of tracheomalacia in symptomatic infants with mediastinal aortic vascular anomalies: preliminary technical experience. Pediatr Radiol 2008;38:82-88.

22. Wiseman NE, Duncan PG, Cameron CB. Management of tracheobronchomalacia with continuous positive airway pressure. J Pediatr Surg 1985; 20:489-493.

23. Arcieri L, Serio P, Nenna R, et al. The role of posterior aortopexy in the treatment of left mainstem bronchus compression. Interact Cardiovasc Thorac Surg 2016;23:699-704.

24. Bairdain S, Zurakowski D, Baird CW, Jennings RW. Surgical treatment of tracheobronchomalacia: a novel approach. Paediatr Respir Rev 2016;19: 16-20.

25. Food and Drug Administration. Safety warning: metallic tracheal stents in patients with benign airway disorders. Available at: https://wayback.archive-it. org/7993/20170112171022/http:/www.fda.gov/Safety/MedWatch/SafetyInformation/
SafetyAlertsforHumanMedicalProducts/ucm153009.html accessed the original page around July 2017.

26. Ando M, Nagase Y, Hasegawa H, Takahashi Y. External stenting: a reliable technique to relieve airway obstruction in small children. $J$ Thorac Cardiovasc Surg 2017;153:1167-1177.

27. Filler RM, Buck JR, Bahoric A, Steward DJ. Treatment of segmental tracheomalacia and bronchomalacia by implantation of an airway splint. J Pediatr Surg 1982;17:597-603.

28. Vasko JS, Ahn C. Surgical management of secondary tracheomalacia. Ann Thorac Surg 1968;6:269-272.

29. Johnston MR, Loeber N, Hillyer P, Stephenson LW, Edmunds LH Jr. External stent for repair of secondary tracheomalacia. Ann Thorac Surg 1980;30:291-296.

30. Blair GK, Cohen R, Filler RM. Treatment of tracheomalacia: eight years' experience. J Pediatr Surg 1986;21:781-785.

31. Vinograd I, Filler RM, Bahoric A. Long-term functional results of prosthetic airway splinting in tracheomalacia and bronchomalacia. J Pediatr Surg 1987;22:38-41.

32. Filler RM, Messineo A, Vinograd I. Severe tracheomalacia associated with esophageal atresia: results of surgical treatment. J Pediatr Surg 1992;27: 1136-1140; discussion 1140-1141.

33. Hagl S, Jakob H, Sebening C, et al. External stabilization of long-segment tracheobronchomalacia guided by intraoperative bronchoscopy. Ann Thorac Surg 1997;64:1412-1420; discussion 1421. 